Tropical Journal of Pharmaceutical Research January 2016; 15 (1): 189-194

ISSN: $1596-5996$ (print); 1596-9827 (electronic)

(c) Pharmacotherapy Group, Faculty of Pharmacy, University of Benin, Benin City, 300001 Nigeria.

All rights reserved.

Available online at http://www.tjpr.org

Original Research Article

http://dx.doi.org/10.4314/tjpr.v15i1.26

\title{
Prevalence and Risk Factors for Brucellosis in Jazan Province, Saudi Arabia
}

\author{
Hussein Ageely ${ }^{1}$, Ibrahim Bani ${ }^{2}$, Abdelrahim Gaffar ${ }^{3}$, Magdeldin Eltigani ${ }^{4}$, Abu \\ Obaida Yassin ${ }^{7}$, Badria Said ${ }^{5}$ and Mohamed Salih Mahfouz ${ }^{3 *}$ \\ ${ }^{1}$ Department of Internal Medicine, ${ }^{2}$ King Saud bin Abdulaziz University for Health Sciences, Riyadh, Saudi Arabia ${ }^{3}$ Department \\ of Family and Community Medicine, Faculty of Medicine, ${ }^{4}$ Department of Medical Lab Technology, College of Applied Medical \\ Sciences, Jazan University, Jazan, Saudi Arabia, ${ }^{5}$ Department of Microbiology, Faculty of Medicine, Jazan University, Jazan, \\ Saudi Arabia
}

*For correspondence: Email: mm.mahfouz@gmail.com

\begin{abstract}
Purpose: Brucellosis is responsible for considerable public health issues involving economic losses due to abortion, loss of milk production and infertility in adult males. The purpose of this study was to determine the sero-prevalence of brucellosis in Jazan Province, Saudi Arabia and assess the possible risk factors.

Methods: An observational cross-sectional study was conducted in three geographical areas of Jazan Province, Saudi Arabia. The study sample included 400 participants from randomly selected primary health care centres. A standardised questionnaire was used to collect information on demographics and risk factors for brucellosis. A $5 \mathrm{ml}$ blood sample was collected from each study participant. The SPSS statistical program was utilised for data analysis.

Results: The overall sero-prevalence of brucellosis in Jazan Province was $13.4 \%$ and was higher among participants $\geq 40$ years old $(20 \%)$ than those $<40$ years $(12 \%)$. Prevalence was significantly higher among rural (39.3 \%; $95 \%$ confidence interval [Cl], 29.8 - 49.7) than urban populations (4.6\%; $95 \%$ Cl, 2.7 - 7.9), in Saudis (14.5 \%; 95 \% Cl, 11.1 - 18.8) than non-Saudis (3.0 \%; 95 \% Cl, 7.0 15.3) and in males (16.4\%; $95 \% \mathrm{Cl}, 12.2$ - 21.6) than females (7.1\%; $95 \% \mathrm{Cl}, 3.7-13.4)$.

Conclusion: These results indicate the need for a vaccination program in Jazan Province and for public awareness campaign activities to combat and eradicate the disease.
\end{abstract}

Keywords: Sero-prevalence, Brucellosis, Milk, Vaccination, Public awareness campaign

Tropical Journal of Pharmaceutical Research is indexed by Science Citation Index (SciSearch), Scopus, International Pharmaceutical Abstract, Chemical Abstracts, Embase, Index Copernicus, EBSCO, African Index Medicus, JournalSeek, Journal Citation Reports/Science Edition, Directory of Open Access Journals (DOAJ), African Journal Online, Bioline International, Open-J-Gate and Pharmacy Abstracts

\section{INTRODUCTION}

Brucellosis is a major zoonotic infection that remains an important public health concern in many parts of the world [1]. In addition to its impact on human health, brucellosis is responsible for considerable public health issues involving economic losses due to abortion, loss of milk production and infertility in adult males [2].
Four important species are pathogenic to humans, such as Brucella melitensis, found primarily in goats, sheep and camels, Brucella abortus in cows, Brucella suis in pigs and Brucella canis in dogs. Brucella spp. differ in their degree of virulence and invasiveness. $B$. melitensis is the most invasive and results in the most severe illness. $B$. abortus is the least invasive and causes the mildest illness. $B$. 
melitensis remains the principal cause of human brucellosis worldwide [3,4].

Brucellosis has a worldwide distribution, but the disease has become rare among most industrialised countries because of routine domestic livestock screening, implementation of effective animal vaccination programs and strict regulations regarding animal importation and other precautionary measures. However, brucellosis remains leading zoonoses in developing countries of the Eastern Mediterranean, including Saudi Arabia [4-6].

Human brucellosis ranks as the number one priority zoonosis among Member States of the Eastern Mediterranean including Saudi Arabia $[8,9]$. In 1999, the World Health Organisation (and Food and Agriculture Organisation Report on Brucellosis) revealed Saudi Arabia to have the highest incidence of human brucellosis in the province [10].

Literature from Saudi Arabia suggests that $B$. melitensis remains the principal cause of human brucellosis, with less frequent infections by $B$. abortus. Furthermore, the natural reservoir for brucellosis is domestic animals, and animal-toanimal transmission is usually venereal or via ingestion of infected tissues or milk [11-14].

Although sero-prevalence data on brucellosis are not available for most provinces in Saudi Arabia $[4,5,11,14]$, no study has assessed the disease in Jazan Province, southwest Saudi Arabia. The aim of this study was to obtain an estimate of the prevalence of human brucellosis in Jazan Province and to identify possible associated risk factors among the people living in this province.

\section{EXPERIMENTAL}

\section{Study design and setting}

An observational cross-sectional survey was conducted in three geographical areas of Jazan Province. Jazan (also called Gizan) is one of the 13 provinces of the Kingdom of Saudi Arabia. It is located on the tropical Red Sea coast in southwestern Saudi Arabia.

\section{Participants and sampling procedures}

A sample size of 400 participants $(\geq 15$ years old) who attended selected primary heath care centres (PHCCs) and signed informed consent were included in the study. The provinces were divided into mountain, coastal and plain areas for sampling purposes. One province was chosen randomly from each area, and two PHCCs were selected.

Probability proportional to the sample size was used to determine the number of participants used from each of the selected PHCCs. The study was conducted from May 2012 - March 2013.

\section{Sample collection and laboratory processing}

A $5 \mathrm{ml}$ blood sample was collected from each individual, centrifuged to separate the serum and dispatched on the same day to the Faculty of Medicine Laboratory. Sera were stored at $-70^{\circ} \mathrm{C}$ for subsequent testing.

The Diagnostic Automation Brucella IgG antibody enzyme-linked immunosorbent assay test kit was used to detect specific IgG antibodies against Brucella in sera. Diluted sera (1:101) and readyto-use standards were pipetted into the wells of a microtiter plate, and the $\lg G$ antibodies in the serum and the immobilised Brucella antigen were bound. After $1 \mathrm{~h}$ of incubation at room temperature, the plate was rinsed with diluted wash solution to remove unbound material. Then, the ready-to-use anti-human-lgG peroxidase conjugate was added and incubated for $30 \mathrm{~min}$. After another wash, the substrate (TMB) solution was added and incubated for 20 min to develop a blue colour. Colour development was terminated by adding the provided stop solution, which changed the colour from blue to yellow. The resulting dye was measured at a wavelength of $450 \mathrm{~nm}$ using the ELx800 Microplate Reader (BioTek, Winooski, VT, USA) with Gen5 software for data output. The calculated absorption values were compared with the standard cut-off values. A sample was considered positive if its value was $>+20 \%$ of the standard cut-off value. Values below the standard cut-off were considered negative.

\section{Data collection and study instrument}

In addition to the blood samples, other demographic and risk factor data were collected through personal face-to-face interviews. A questionnaire was used to record age, sex, nationality, place of residence, consumption of raw milk (yes or no), consumption of camel's milk (yes or no), consumption of cheese (yes or no), contact with a dead animal (yes or no), contact with animals (yes or no) and other risk factors.

\section{Statistical analysis}

The overall sero-prevalence of brucellosis among the study participants was calculated using $95 \%$ 
confidence intervals $(\mathrm{Cl})$. The chi-square test or Fisher's exact test was used to evaluate the sero-prevalence of brucellosis among the different sub-groups. Crude odds ratios (ORs) were obtained by univariate analysis to determine the association of each variable with brucellosis sero-prevalence. All statistical tests were two-sided; and a $p<0.05$ was considered significant. The statistical analysis was performed using SPSS ver. 17.0 (SPSS Inc. Chicago, IL, USA) software.

\section{Ethical considerations}

Ethical approval for this study was obtained from the Ethics Committee of the Faculty of Medicine, Jazan University. Informed written consent was obtained from all participants prior to involvement in the study.

\section{RESULTS}

Table 1 shows the demographic characteristics of the study population. A total of 350 participants provided signed consent and were included (response rate, $87.5 \%$ ). Almost $50 \%$ of the subjects were $<30$ years old; majority of them were Saudi $(90 \%)$ males (68\%) and were living in an urban area (74.6\%).

Table 2 shows the brucellosis sero-prevalence level in Jazan Province. The overall seroprevalence of brucellosis in Jazan Province was $13.4 \%$ and higher among those $>40$ years old. Prevalence was significantly higher among rural (39.3\%; $95 \%$ Cl, 29.8-49.7) versus urban (4.6 $\%$; $95 \% \mathrm{Cl}, 2.7-7.9)$ populations, Saudis (14.5 $\% ; 95 \% \mathrm{Cl}, 11.1-18.8)$ versus non-Saudis $(3.0$ $\%$; $95 \% \mathrm{Cl}, 0.7-15.3)$ and males (16.4\%; $95 \%$ $\mathrm{Cl}, 12.2-21.6)$ versus females $(7.1 \% ; 95 \% \mathrm{Cl}$, 3.7-13.4).

Table 3 shows the association between certain factors and brucellosis seropositivity in the Jazan Province population. Seropositivity was significantly associated with keeping goats/sheep in the home, contact with dead animals in the past year and drinking raw milk. No significant association was found between seropositivity and keeping cows in the home, drinking camel's milk, contact with animal fluids or eating locally made cheese.

Table 4 illustrates the results of the multivariate logistic regression analysis. The analysis showed that seropositivity was significantly association with contact with dead animals in the past year (OR, 5.04; $p=0.002$ ), keeping goats/sheep in the home (OR, 3.80; $p=0.002)$, drinking raw milk (OR, 2.87; $p=0.015)$ and drinking camel's milk (OR, 0.31; $p=0.010)$.

Table 1: Demographic profile of the study population

\begin{tabular}{|c|c|c|}
\hline Characteristic & $N$ & $\%$ \\
\hline \multicolumn{3}{|l|}{ Age group (years) } \\
\hline $15-19$ & 97 & 27.7 \\
\hline 20-29 & 81 & 23.1 \\
\hline 30-39 & 64 & 18.3 \\
\hline $40-49$ & 44 & 12.6 \\
\hline$>50$ & 41 & 11.7 \\
\hline Not specified & 23 & 6.6 \\
\hline \multicolumn{3}{|l|}{ Sex } \\
\hline Male & 238 & 68.0 \\
\hline Female & 112 & 32.0 \\
\hline \multicolumn{3}{|l|}{ Nationality } \\
\hline Saudi & 317 & 90.6 \\
\hline Non-Saudi & 33 & 9.4 \\
\hline \multicolumn{3}{|l|}{ Residence } \\
\hline Rural & 89 & 25.4 \\
\hline Urban & 261 & 74.6 \\
\hline \multicolumn{3}{|l|}{ Occupation } \\
\hline Working & 132 & 37.7 \\
\hline Not working & 67 & 19.1 \\
\hline Student & 104 & 29.7 \\
\hline Not stated & 47 & 13.4 \\
\hline \multicolumn{3}{|l|}{ Type of housing } \\
\hline Traditional & 199 & 56.9 \\
\hline Villa & 41 & 11.7 \\
\hline Apartment & 105 & 30.0 \\
\hline Not stated & 4 & 1.4 \\
\hline Total & 350 & 100 \\
\hline
\end{tabular}

\section{DISCUSSION}

This is the first study to examine the seroprevalence of and risk factors for human brucellosis in Jazan Province, Saudi Arabia. The results revealed that the overall sero-prevalence of brucellosis in Jazan Province was $13.4 \%$, which was higher among those $>40$ years old. Prevalence was higher among males (16.4\%) than females $(7.1 \%)$, which was a similar finding in many studies in Saudi Arabia and other Arabian countries [15-17]. The higher rate of brucellosis sero-prevalence in males compared with females was probably due to a greater involvement of men in domestic animal farming and product handling. The overall prevalence was similar to that in other studies conducted in Saudi Arabia [17].

We found a higher sero-prevalence rate in rural areas (39.3\%), which was higher than that reported in other parts of Saudi Arabia (26.2 \%) [18]. The variation in the prevalence rates of 
Ageely et al

Table 2: Level of brucellosis sero-prevalence in Jazan Province, Saudi Arabia

\begin{tabular}{ccccc}
\hline Characteristic & $\begin{array}{c}\text { N-positive/ } \\
\text { N-tested }\end{array}$ & Prevalence & 95\% Cl & $P$-value \\
\hline Age group (years) & $(8 / 97)$ & 8.2 & $(4.3-15.5)$ & 0.205 \\
$15-19$ & $(10 / 81)$ & 12.3 & $(6.9-21.3)$ & \\
$20-29$ & $(11 / 64)$ & 17.2 & $(9.9-28.3)$ & \\
$30-39$ & $(9 / 44)$ & 20.5 & $(11.2-34.6)$ & \\
$40-49$ & $(8 / 41)$ & 19.5 & $(10.3-34.1)$ & \\
$>50$ & $(35 / 89)$ & 39.3 & $(29.8-49.7)$ & 0.000 \\
Residence type & $(12 / 261)$ & 4.6 & $(2.7-7.9)$ & \\
Rural & & & & \\
Urban & $(46 / 317)$ & 14.5 & $(11.1-18.8)$ & 0.066 \\
Nationality & $(1 / 33)$ & 3.0 & $(0.7-15.3)$ & \\
Saudi & $(39 / 238)$ & 16.4 & $(12.2-21.6)$ & 0.018 \\
Non-Saudi & $(8 / 112)$ & 7.1 & $(3.7-13.4)$ & \\
Sex Male & $(47 / 350)$ & 13.4 & $(10.3-17.4)$ & \\
Female & & &
\end{tabular}

Table 3: Risk factors associated with human brucellosis seropositivity in the population of Jazan Province, Saudi Arabia

\begin{tabular}{|c|c|c|c|c|}
\hline Factor & N (\%) Sero-positive & $\begin{array}{c}\mathbf{N}(\%) \text { Sero- } \\
\text { negative }\end{array}$ & OR $(95 \% \mathrm{Cl})$ & $P$-value \\
\hline \multicolumn{5}{|l|}{ Cows in the home $(n=347)$} \\
\hline Yes & $2(8.3)$ & $22(91.7)$ & $0.58(0.13-2.5)$ & 0.416 \\
\hline No & $44(13.6)$ & $279(86.4)$ & & \\
\hline \multicolumn{5}{|l|}{ Goats/sheep in the home $(n=348)$} \\
\hline Yes & $34(30.1)$ & $79(69.9)$ & $8.0(3.9-16.2)$ & \\
\hline No & $12(5.1)$ & $223(94.9)$ & & 0.000 \\
\hline \multicolumn{5}{|l|}{$\begin{array}{l}\text { Any contact with dead animals in } \\
\text { the past year }(n=346)\end{array}$} \\
\hline Yes & $16(59.3)$ & $11(40.7)$ & $14.0(6.0-32.9)$ & \\
\hline No & $30(9.4)$ & $289(90.6)$ & & \\
\hline \multicolumn{5}{|l|}{ Drinking raw milk ( $\mathrm{n}=341)$} \\
\hline Yes & $26(29.5)$ & $62(70.5)$ & $5.1(2.7-9.9)$ & 0.000 \\
\hline No & $19(7.5)$ & $234(92.5)$ & & \\
\hline \multicolumn{5}{|l|}{ Drinking camel's milk ( $\mathrm{n}=345)$} \\
\hline Yes & $14(12.4)$ & $99(87.6)$ & $0.88(0.41-1.73)$ & 0.719 \\
\hline No & 32 (13.8) & $200(86.2)$ & & \\
\hline \multicolumn{4}{|l|}{$\begin{array}{l}\text { Any contact with animal fluids } \\
(\mathrm{n}=347)\end{array}$} & 0.609 \\
\hline Yes & $1(8.3)$ & $11(91.7)$ & $0.59(0.07-4.6)$ & \\
\hline No & $45(13.4)$ & $290(86.6)$ & & \\
\hline \multicolumn{5}{|l|}{$\begin{array}{l}\text { Eating locally made cheese } \\
(\mathrm{n}=343)\end{array}$} \\
\hline Yes & $1(4.2)$ & $23(95.8)$ & & 0.178 \\
\hline No & $44(13.8)$ & $275(86.2)$ & $0.27(0.04-1.2)$ & \\
\hline
\end{tabular}

Table 4: Results of the multivariate logistic regression analysis

\begin{tabular}{lcccccc}
\hline Variable & & & Adjusted & \multicolumn{2}{c}{ 95\% Cl for OR } \\
S.E. & Wald & P-value & OR & Lower & Upper \\
\hline Sheep in the house (yes) & .438 & 9.299 & .002 & 3.80 & 1.61 & 8.97 \\
Contact with dead animals (yes) & .527 & 9.427 & .002 & 5.04 & 1.79 & 14.17 \\
Drinking camel's milk (yes) & .456 & 6.718 & .010 & 0.31 & 0.13 & 0.75 \\
Sex (male) & .482 & 2.920 & .087 & 2.28 & 0.88 & 5.86 \\
Drinking milk (yes) & .434 & 5.910 & .015 & 2.87 & 1.22 & 6.72 \\
\hline
\end{tabular}


brucellosis among different geographical regions may be due to variations in disease prevalence among animals, occupational contact or the social habits of different populations. The seroprevalence of brucellosis was found to increase with age, which is consistent with observations made in Iran, Jordan, Lebanon and Kuwait $[19,20]$. The lower sero-prevalence rates found in teenagers, compared with adults, may be due to greater exposure of adults to livestock.

A major risk factor, seen in $5.9 \%$ of sero-positive cases, was contact with dead animals. Brucellosis sero-positivity was significantly associated with keeping goats/sheep in the house, contact with dead animals during the past year and drinking any kind of raw milk. These findings agree with those of other studies [8]. Drinking camel's milk is a common practice and custom in Saudi Arabia, but it had no association with brucellosis sero-positivity.

\section{Limitations of the study}

Although the present study is the first to consider brucellosis in Jazan Province, it has some significant limitations. First, the study was based on a relatively small sample size, so the brucellosis prevalence results should be interpreted carefully. Second, our participants were patients attending Jazan Province PHCCs and thus may not truly represent the Jazani population. Finally, this was a cross-sectional study design, which is not suitable for assessing brucellosis risk factors, as direct and causal relationships among the variables cannot be established properly.

\section{CONCLUSION}

This study confirmed the risk of brucellosis in Jazan Province. The current results confirm the need for a vaccination program and a public awareness campaign to limit and eradicate the disease. We strongly recommend the development of methods to detect brucellosis, initiate early treatment and reduce complications.

\section{ACKNOWLEDGEMENT}

The authors thank the Deanship of Scientific Research, Jazan University for funding this study. We also acknowledge the assistance provided by the Jazan Directorate of Health, Saudi Arabia. Thanks to all of the study survey participants.

\section{REFERENCES}

1. Cooper CW. Risk factors in transmission of brucellosis from animals to humans in Saudi Arabia. Trans Royal Soc Trop Med Hygiene 1992; 86(2): 206-209.

2. Musallam II, Abo-Shehada M, Omar M, Guitian J. Crosssectional study of brucellosis in Jordan: Prevalence, risk factors and spatial distribution in small ruminants and cattle. Preventive Veterinary Medicine 2015; 118(4): 387-396.

3. Memish Z. Brucellosis control in Saudi Arabia: Prospects and Challenges J. Chemother 2001; 13 Suppl 1: 11-17.

4. Al-Eissa Y A. Brucellosis in Saudi Arabia: Past, present and future. Ann. Saudi Med. 1999; 19.5: 403-405.

5. Al Tawfiq J A, AbuKhamsin A. A 24-year study of the epidemiology of human brucellosis in a health-care system in Eastern Saudi Arabia. J Infect Public Health 2009; 2: 81-85.

6. Dean AS, Crump L, Greter H, Schelling E, Zinsstag J. Global burden of human Brucellosis: A Systematic review of disease frequency. PLoS Negl Trop Dis 2012; 6(10): e1865.

7. Mantur BG, Amarnath SK, Shinde RS. Review of clinical and laboratory features of human Brucellosis 2007; 25(3): 188-202.

8. Meky FA, Hassan EA, Abdel Hafez AM, Aboul Fetouh AM, El Ghazali SM. Epidemiology and risk factors of brucellosis in Alexandria governorate East Medit Health J 2007; 13(3): 677-685.

9. Abdou A. Fifty years of veterinary public health activities in the Eastern Mediterranean Province. East Medit Health J 2000. 6(4): 796-807.

10. WHO/MZCP Report on the Third Workshop on human and animal Brucellosis epidemiological surveillance in the MZCP Countries Damascus, Syrian Arab Republic, 4-5 May 1998.

11. Kambal A M, Maghoub E S, Jamjoom G A, Chowdhury $M$ N. Brucellosis in Riyadh, Saudi Arabia: A microbiological and clinical study. Trans. R. Soc. Trop. Med. Hyg. 1983, 77: 820-824.

12. Bilan NE, Jamjoom GA, Bobo RA, Aly OF, El-Nashar NM. Brucellosis in the Asir province of Saudi Arabia. Saudi Med J. 1991; 12: 37-41.

13. Bilan NE, Jamjoom GA, Bobo RA, Aly OF, El-Nashar NM. Study of the knowledge, attitude and practice (KAP) of a Saudi Arabian community towards the problem of brucellosis. J. Egypt Public Health Assoc. 1991; 66 (12): 227-238.

14. Al-Sekait MA. Seroepidemiological survey of brucellosis antibodies in Saudi Arabia. Ann Saudi Med 1999; 19(3): 219-222.

15. Al Ali AM, Alluwaimi AM. The Incidents of Human Brucellosis in Al-Ahsaa area, Saudi Arabia, Scientific J King Faisal Univ 2009; 10(2): 1430.

16. Fallatah SM, Oduloju AJ, Al-Dusari SN, Fakunle YM. Human brucellosis in Northern Saudi Arabia. Saudi Med J. 2005; 26: 1562-1566. 
Ageely et al

17. Elbeltagy KE. An epidemiological profile of brucellosis in Tabuk Province, Saudi Arabia. East Medit Health J, 2001; 7(4/5): 790-798.

18. Al-Sekait MA. Seroepidemiology survey of brucellosis antibodies in Saudi Arabia. Ann Saudi Med 1999; 19(3): 219-222.
19. Araj GF, Azzam RA. Seroprevalence of antibodies among persons in high-risk occupation in Lebanon. Epidemiol Infect 1996; 117: 281-288.

20. Lulu AR, Arja GF, Khateeb MY, Yusuf AR, Ferech FF. Human brucellosis in Kuwait Q J Med 1998; 66: 39-44. 